\title{
Nurses' Application of International Patient Safety Goals at Accredited
}

\author{
and Non-accredited Hospitals
}

\author{
Amir Gamal Attia Tahoun ${ }^{1}$, Sanaa Moustafa Safan ${ }^{2}$, Ebtesam Saeed Ahmed ${ }^{3}$ \\ (1)(B.Sc. Nursing 2010, Cairo University), Nursing Specialist at Al-Sadat General Hospital \\ (2)Assistant Professor of Nursing Administration, Faculty of Nursing, Menoufia University \\ (3)Assistant Professor of Nursing Administration, Faculty of Nursing, Benha University
}

\begin{abstract}
Background: Patient safety is an essential component in the quality of patient care. It remains a challenge for developing countries. Assessment of application of international patient safety goals in healthcare organizations is becoming an integral component to improve patients' safety. The study aimed to assess nurses' application of international patient safety goals at accredited and non-accredited hospitals. Research design: A comparative design was utilized to conduct this study. Setting: The study was conducted at general intensive care units (ICU) in Benha University Hospital (non-accredited hospital) and Elaraby International Hospital (accredited hospital). Sample: All available 112 staff nurses working at the above mentioned settings distributed as following 60 staff nurses at Benha University Hospital and 52 staff nurses' at Elaraby International Hospital. Tools for data collection: Three tools were used. I: Personal and work characteristics of studied staff nurses, II: International patient safety goals' questionnaire and III: Observational checklist for international patient safety goals practice. Results: $97.8 \%$ \& $94.3 \%$ of studied staff nurses had good knowledge and competently applied practice level at accredited hospital respectively. While, $30.1 \%$ had good knowledge and $76.1 \%$ of them had incompetently applied practice level at non-accredited hospital about international patient safety goals. Conclusion: There was a positive statistical significance correlation between studied staff nurses' knowledge and practice of international patient safety goals at accredited and non-accredited hospitals. There was highly statistical significance difference between accredited and nonaccredited hospitals regarding knowledge and practice of international patient safety goals among studied staff nurses. Recommendations: Educational programs and training courses should be developed and implemented for staff nurses' about application of international patient safety goals and how it can be used to improve patient safety at non-accredited hospitals.
\end{abstract}

Key words: Accredited, International patient safety goals, nurses' application and non-accredited.

\section{Introduction}

Patient safety is the fundamental cornerstone of the health care system and remains a global problem that affects all developed and developing countries and the accredited and non-accredited hospitals. And, it is the prevention of harm to patient. Emphasis placed on the system of care delivery that prevents errors, learns from the errors that do occur and is built on a culture of safety that involves health care professionals, organizations, and patient (Theodosios, 2014 and Zhan, 2016).

The importance of patient safety is growing worldwide; and every day nurses 
face various challenges in how to provide safe care for their patient. Patient safety is often considered a component of quality thus, practices to improve patient safety improve the overall quality of care. Collectively and individually nurses have a professional responsibility and duty to protect all patient from harm (Brasaite, Kaunonen, Martinkenas, Mockiene and Suominen, 2017).

Nursing staff has a crucial role in understanding and applying the six international patient safety goals to minimize hazards and errors. In addition to they participate in almost every aspect of healthcare delivery, they perceive patient safety as primarily their responsibility (Aboshaiqah and Baker, 2013; Khater, Akhu-Zaheya, Al-Mahasneh and Khater, 2015).

The international patient safety goals have become a critical method by that the joint commission international promotes and enforces major changes in patient safety. The criteria used for determining the value of these goals, and required revisions to them, are based on the merit of their impact, cost, and effectiveness Moreover, international patient safety goals (IPSG) were established to assist health care organizations to address specific areas of concern regarding patient safety, that include; $1^{\text {st }}$ goal: Identifying patient correctly, $2^{\text {nd }}$ goal: Improving effective communication among health care givers, $3^{\text {rd }}$ goal: Improving the safety of high alert medications, $4^{\text {th }}$ goal: Ensuring correct site, correct procedure and correct patient surgery, $5^{\text {th }}$ goal: Reducing the risk of healthcare associated infections and finally $6^{\text {th }}$ goal: Reducing the risk of patient harm resulting from falls (Joint commission international (JCI), 2014).
Accreditation is a vital tool to support efforts to protect patient safety. An accredited hospital assures the best practices in a safe environment and that the patient is in safe care. Furthermore, joint commission international (JCI) accreditation appears to have a significant effect on patient and staff safety improvement (Mousavi et al., 2016).

This study aimed to assess nurses' application of international patient safety goals at accredited and non-accredited hospitals.

\section{Aim of the study}

This study aimed to assess nurses' application of international patient safety goals at accredited and non-accredited hospitals.

\section{Research Questions}

1. What is the level of nurses' knowledge about international patient safety goals at study setting?

2. What is the level of nurses' practices about the application of international patient safety goals at study setting?

3. What is the difference between accredited and non-accredited hospitals regarding the application of international patient safety goals?

\section{Subjects and method}

\section{Research design:}

Comparative design was utilized to conduct this study.

\section{Setting:}

The current study was conducted at general intensive care units at Benha University Hospital that is non-accredited hospital and Elaraby International Hospital that is JCI (Joint Commission International) accredited from May, 2018. The total number of beds at 
Benha University Hospital is 880 beds. The hospital composed of three separated buildings; medical building by capacity 478 beds, it constructed from 14 departments as the following; (5) general medical, (3) pediatric, (1) thoracic, (1) psychiatric, (1) neurology, (1) dermatology, (1) rheumatology and (1) cardiology department. And, there were nine critical care units; general intensive care unit(ICU), medium ICU, emergency ICU, hepatic ICU, cardiac care unit(CCU), thoracic ICU, cardiothoracic ICU, pediatric ICU and neonatal ICU. Surgical building by capacity 384 beds, it distributed into 11 departments as the following; (4) general surgical, (3) orthopedic, (2) urology, (1) obstetric and (1) ear nose throat department. And, ophthalmology building composed of 18 beds and contained (1) department.

The total number of beds at Elaraby International Hospital at Menoufia governate is 300 beds and it constructed from general intensive care (ICU), cardiology care unit (CCU), neonatal ICU, emergency department, renal dialysis unit, 4 inpatient departments. The bed capacity at general intensive care unit at Benha University Hospital is 22 beds. While, at Elaraby International Hospital is 16 beds. So, the total bed capacity at both hospitals is 38 beds.

\section{Sample:}

All available 112 staff nurses' working at the above mentioned study settings and distributed as following, 60 staff nurses at Benha University Hospital (non-accredited hospital) and 52 staff nurses' at Elaraby International Hospital (accredited hospital).

\section{Tools of data collection:}

The data of the present study was collected by using three tools as following;

\section{Tool (I): Personal and work characteristics of studied staff nurses}

It was designed by the investigator in the light of current relevant studies and researches to assess staff nurses' personal characteristics as; hospital name, age, gender, educational level, years of experience, marital status, work shift and previously training courses about patient safety goals.

\section{Tool (II): International patient safety goals' questionnaire}

It was adopted from Joint Commission International, (2014) and modified by the investigator after reading a literature to suit the nature of the study and it was aimed to assess studied staff nurses' knowledge levels of international patient safety goals in the previously mentioned settings. It included 45 items grouped under six main goals as the following; patient identification correctly (9 items), improve effective communication (6 items), improve the safety of high alert medications (9 items), ensure correct site, correct-procedure, correct- patient surgery (7 items), reduce the risk of health careassociated infections ( 8 items), and reduce the risk of patient harm resulting from falls (6 items).

\section{Scoring system:}

The studied staff nurse' answers were compared by a model key answer, where scored as; correct answer had score 2, and incorrect answer had score 1. Finally the scores of each goal summed up and converted to percent scores. Range of scores from (4590 ) and cut point was done at $60 \%=54$ point. In this respect the level of nurses' knowledge regarding international patient safety goals was categorized as the following; Poor knowledge level $<60 \%$ equal to $<54$ points, average knowledge level from $60 \%$ to $<75 \%$ was ranged from 54-< 68 points and good 
knowledge level $\geq 75 \%$ equal to $\geq 68$ points (Zakaria, Hamzah, Yamin, Hamidon, Ariffin etal., 2019).

Tool (III): Oobservational checklist for international patient safety goals' practice:

It was adopted from Joint Commission International, (2014) to investigate nurses' application of international patient safety goals in hospitals. It was modified by the investigator to suit the nature of the study as added some statements as; there is a written and announced policy for each goal in the unit, kept insulin and heparin in the unit by color coded label and there is a commitment to disinfect insertion site (cannula, central venous line) before any invasive procedure .It included 36 items grouped under six main goals as the following; patient identification correctly 7 items, improve effective communication 5 items, improve the safety of high alert medications 11 items, ensure correct site, correct-procedure, correct- patient surgery 2 items, reduce the risk of health careassociated infections 8 items, and reduce the risk of patient harm resulting from falls 3 items.

\section{Scoring system:}

The nurses' practice level was evaluated by the investigator in clinical setting by using a three point Likert Scale ranged from 1-3 as; 3 apply, 2 to some extent that meaning partially applied and 1 not apply. Finally the scores of each goal summed up and converted to percent scores. Range of scores from 36-108 and cut point was done at $60 \%=65$ points. Accordingly level of nurse' practice was categorized as the following; incompetently apply $<60 \%$ and competently apply $\geq 60 \%$ (Ebrahim, Mohamed and Ahmed, 2019).

\section{Ethical consideration:}

The study was conducted by carefully attention to ethical standards of research and rights of the participants. Interview was hold between the investigator and studied staff nurses at Benha University Hospital (nonaccredited hospital) and Elaraby International Hospital (accredited hospital) to gain their oral approval and cooperation. Studied staff nurses were assured that all gathered data was used for research purpose only and the study was harmless. Additionally, allow to staff nurses have the right to withdraw from the study at any time by out reasons and confidentially of the gathered data and results were secured. To ensure scientific honestly, the investigator used bracketing and intuiting to avoid bias.

\section{Content validity:}

Tools of data collection were translated into Arabic and were revised by Jury of five Experts' in the field of Nursing Administration from Faculty of Nursing; two Professors Cairo and Menoufia University, three Assistant Professors from Cairo, Menoufia and Ain shams University. The validity of the tools aimed to judge its clarity, comprehensiveness, relevance, simplicity and accuracy. Based on the experts' prospective minor modifications were done and the investigator developed the final validated form of tools. It took one month August, 2019.

\section{Reliability of the tools:}

Reliability of the tools was applied by using Cronbach's Alpha coefficient test to measure international consistency of the study results and the value for international patient safety goals questionnaire was $\alpha=0.946$ and observational checklist for international patient safety goals practice was $\alpha=0.871$ that reflect accepted internal consistency of the tools.

\section{Pilot Study:}

The pilot study was carried out on $10 \%$ of the sample (12) members. Those members were included in the actual study. The pilot study 
was done to assess the tool feasibility, applicability and time needed to fill each sheet. The data obtained from the pilot study was analyzed. Accordingly, modification needed were made such as, omission, addition and rewording.

\section{Field work:}

This phase took two months from the beginning of October, 2019 to the end of November, 2019. At the beginning, the investigator welcomed the staff nurses' and gave a brief idea about the aim and purpose of the study.

The investigator was available at the Benha University Hospital (non-accredited hospital) three days/weekly (Saturday, Wednesday and Thursday) and at Elaraby International Hospital (accredited hospital) at two days/weekly (Sunday and Monday) from 10:00 am and extended to 12:00 pm.

- Then, the investigator collected data from staff nurses' by using the questionnaire. Average number of staff nurses' collected was 2-3 nurses per day at Benha University Hospital and average was 3-4 nurses per day at Elaraby International Hospital.

The time required for finishing each question was around 20-25 minutes for international patient safety goals questionnaire and 30-40 minutes for observational checklist of international patient safety goals practice by investigator.

- $\quad$ The appropriate time for data collection was determined according to type of work and workload; sometimes it was in the middle of the shift and other time before the end of the shift in the presence of the investigator to ascertain all questions were answered. The filled forms were revised to cheek their completeness to avoid any missing data.

\section{Statistical design:}

The collected data organized, tabulated and statistically analyzed using statistical package for social science (SPSS) Version 21 for windows, running on IBM compatible computer. Descriptive statistics were applied as frequency, percentage, means arithmetic and standard deviation. Chi-square test $\left(\mathrm{X}^{2}\right)$ was used to study association between two qualitative variables. In addition, independent sample t test was used to compare mean scores of different group. In addition correlation coefficient ( $r$ ) test was used to estimate the closeness association between variables. The P-value is the probability that an observed difference is due to chance and not a true difference A significant level value was considered when $\mathrm{p}$-value $\leq 0.05$ and a highly significant level value was considered when $\mathrm{p}$ value $\leq 0.001$, while $p$ - value $>0.05$ indicates non-significant results.

\section{Results:}

Table (1): Illustrates that, more than half $(60.0 \% \& 51.9 \%)$ of the studied staff nurses' were aged from 20 to less than 25 years old at Benha University and Elaraby International Hospitals respectively. Regarding gender at Benha University Hospital more than three quarters $(76.7 \%)$ of studied staff nurses' were females, while at Elaraby International Hospital about three fifth $(59.6 \%)$ of them were males. Moreover, about three quarters $(73.3 \%)$ and more than half $(51.9 \%)$ of studied staff nurses' were married at Benha University and Elaraby International Hospitals respectively. As far as, educational levels the vast majority $(90.0 \%)$ of studied staff nurses' at Benha University Hospital had associate degree of nursing, on the other hand nearly three quarters $(71.2 \%)$ of them had Bachelor of nursing science at Elaraby International Hospital .Additionally more than half (53.3\% 
\&55.8\%) of studied staff nurses had experience less than 5 years at Benha University and Elaraby International Hospitals respectively. Regarding, working shifts about half $(46.2 \%)$ and about two thirds $(63.3 \%)$ of studied staff nurses' worked at all shifts at Benha University and Elaraby International Hospitals respectively. Additionally, the majority (70.0\%) of studied staff nurses' at Benha University Hospital hadn't attended previous courses; on the contrary, the vast majority $(98.1 \%)$ of them at Elaraby International Hospital had attended previous courses about patient safety.

Figure (1): Clarifies that, the vast majority (97.8\%) and more than one quarter $(30.1 \%)$ of studied staff nurses had good knowledge level about international patient safety goals at accredited (Elaraby International) and nonaccredited (Benha University) hospitals respectively. On the other hand, the lowest percentage $(1.0 \%)$ and about two fifths $(41.6 \%)$ of them had poor knowledge level about international patient safety goals at accredited (Elaraby International) and nonaccredited (Benha University) hospitals respectively.
Figure (2): Clarifies that, the vast majority $(94.3 \%)$ of studied staff nurses competently applied international patient safety goals at accredited hospital (Elaraby International). Conversely, about three quarter $(76.1 \%)$ of them incompetently applied international patient safety goals at non-accredited hospital (Benha University).

Table (2): Shows that, there was positive statistically significant correlation between studied staff nurses' knowledge and practice of international patient safety goals at accredited and non-accredited hospitals. That is means when knowledge increased the practice increased in the same line.

Table (3): Presents that, there was highly statistically significant difference $(p \leq 0.001)$ between accredited and non-accredited hospitals regarding knowledge of international patient safety goals among studied staff nurses.

Table (4): Shows that, there was highly statistically significant difference $(p \leq 0.001)$ between accredited and non-accredited hospitals regarding the application of international patient safety goals among studied staff nurses. 
Table (1): Distribution of the studied staff nurses regarding their personal and work characteristics at the study setting $(n=112)$

\begin{tabular}{|c|c|c|c|c|}
\hline \multirow[t]{2}{*}{$\mathrm{C}_{\text {Variables }}^{\text {Hospital }}$} & \multicolumn{2}{|c|}{$\begin{array}{c}\text { Staff nurses at Elaraby } \\
\text { International Hospital } \\
\text { (accredited) } \mathrm{n}=\mathbf{5 2}\end{array}$} & \multicolumn{2}{|c|}{$\begin{array}{c}\text { Staff nurses at Benha } \\
\text { University Hospital } \\
\text { (non-accredited) } n=60\end{array}$} \\
\hline & No. & $\%$ & No. & $\%$ \\
\hline \multicolumn{5}{|l|}{ Age (years) } \\
\hline $20-<25$ & 27 & 51.9 & 36 & 60.0 \\
\hline $25-<30$ & 16 & 30.8 & 24 & 40.0 \\
\hline $30-35$ & 9 & 17.3 & 0 & 0.0 \\
\hline \multicolumn{5}{|l|}{ Gender } \\
\hline Female & 21 & 40.4 & 46 & 76.7 \\
\hline Male & 31 & 59.6 & 14 & 23.3 \\
\hline \multicolumn{5}{|l|}{ Marital status } \\
\hline Married & 27 & 51.9 & 44 & 73.3 \\
\hline Un married & 25 & 48.1 & 16 & 26.7 \\
\hline \multicolumn{5}{|l|}{ Educational level } \\
\hline Associate degree of nursing & 14 & 26.9 & 54 & 90.0 \\
\hline Bachelor of nursing science & 37 & 71.2 & 6 & 10.0 \\
\hline Master degree in nursing & 1 & 1.9 & 0 & 0.0 \\
\hline \multicolumn{5}{|l|}{ Years of experience } \\
\hline$<5$ years & 29 & 55.8 & 32 & 53.3 \\
\hline $5-<10$ years & 17 & 32.7 & 22 & 36.7 \\
\hline $10-15$ years & 6 & 11.5 & 6 & 10.0 \\
\hline \multicolumn{5}{|l|}{ Work shift } \\
\hline Morning & 0 & 0.0 & 10 & 16.7 \\
\hline afternoon & 0 & 0.0 & 5 & 8.3 \\
\hline Night & 14 & 26.9 & 5 & 8.3 \\
\hline Rotate & 24 & 46.2 & 38 & 63.4 \\
\hline 24 hours (overall day) & 14 & 26.9 & 2 & 3.3 \\
\hline \multicolumn{5}{|c|}{ Previous training courses about patient safety } \\
\hline Yes & 51 & 98.1 & 18 & 30.0 \\
\hline No & 1 & 1.9 & 42 & 70.0 \\
\hline
\end{tabular}




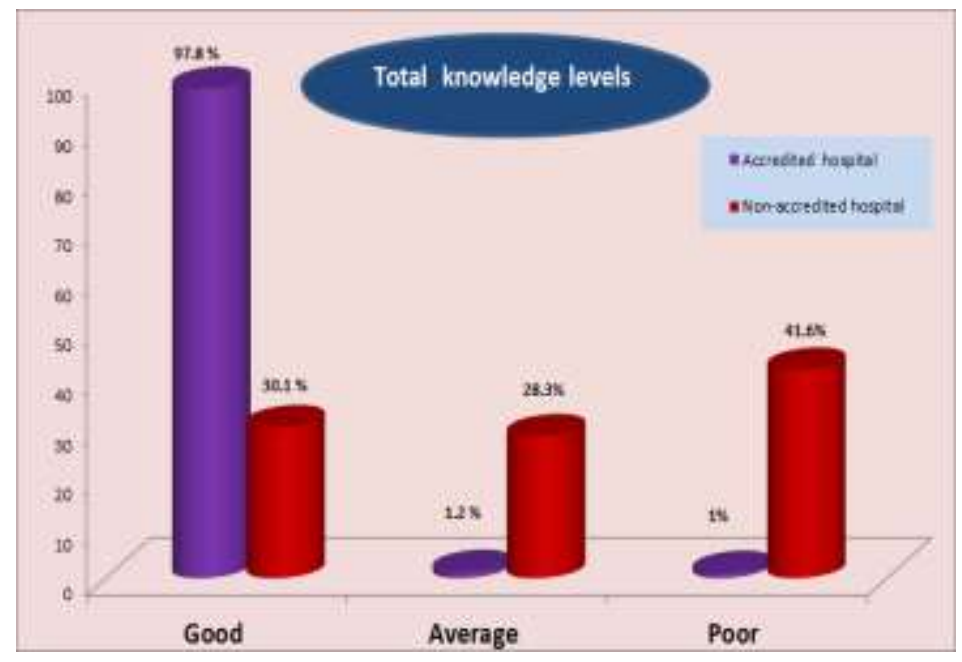

Figure (1): Total knowledge levels of international patient safety goals among studied staff nurses' at study settings

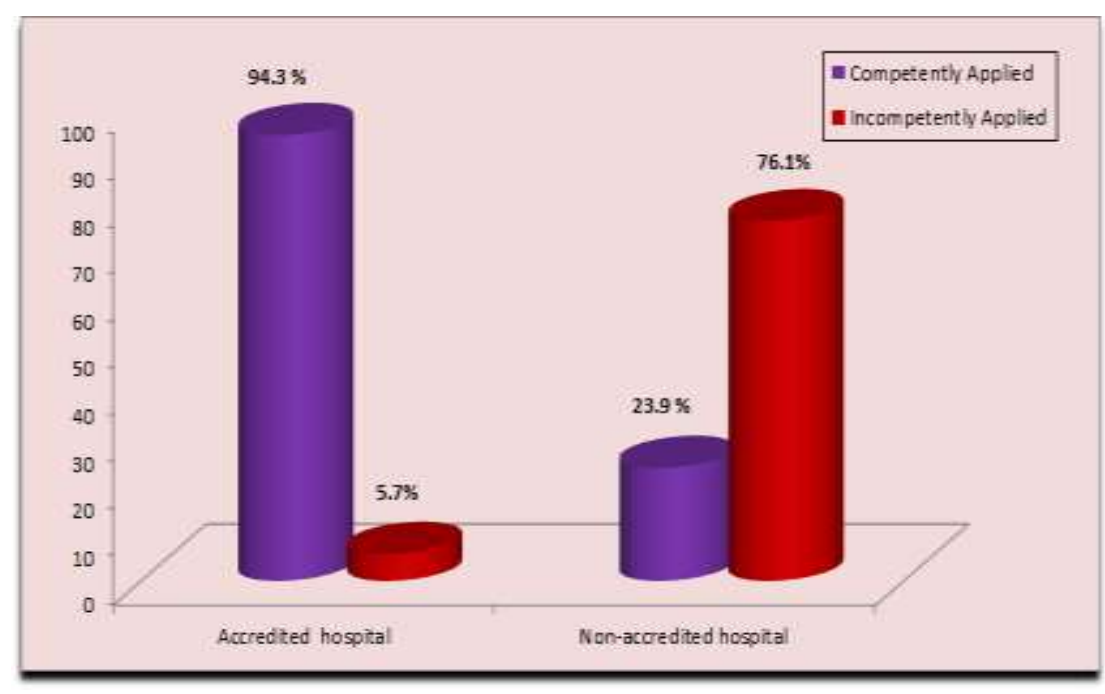

Figure (2): Total practice levels of international patient safety goals among studied staff nurses' at study settings

Table (2): Correlation between studied staff nurses' knowledge and practice of international patient safety goals at study setting

\begin{tabular}{|c|c|c|c|c|}
\hline \multirow{4}{*}{$\begin{array}{c}\text { Staff Nurses' practice of } \\
\text { international patient safety } \\
\text { goals }\end{array}$} & \multicolumn{4}{|c|}{$\begin{array}{l}\text { Staff Nurses' knowledge regarding international patient } \\
\text { safety goals }\end{array}$} \\
\hline & \multicolumn{2}{|c|}{$\begin{array}{l}\text { Elaraby International } \\
\text { Hospital (accredited) }\end{array}$} & \multicolumn{2}{|c|}{$\begin{array}{l}\text { Benha University Hospital } \\
\text { (non-accredited }\end{array}$} \\
\hline & $\mathrm{r}$ & $\mathrm{p}$ & $\mathrm{r}$ & $\mathrm{p}$ \\
\hline & 0.65 & $* * 0.001$ & 0.463 & $* 0.047$ \\
\hline
\end{tabular}

*statistical significance difference $(\mathbf{p} \leq \mathbf{0 . 0 5})$ 
Table (3): Comparison between accredited and non-accredited hospitals regarding knowledge of international patient safety goals among studied staff nurses $(n=112)$

\begin{tabular}{|c|c|c|c|c|c|c|c|}
\hline \multirow[t]{2}{*}{ International patient safety goals } & \multirow[t]{2}{*}{$\begin{array}{c}\text { Maximum } \\
\text { score }\end{array}$} & \multicolumn{2}{|c|}{$\begin{array}{c}\text { Elaraby } \\
\text { International } \\
\text { Hospital } \\
\text { (accredited) } \\
\text { n=52 } \\
\end{array}$} & \multicolumn{2}{|c|}{$\begin{array}{c}\text { Benha University } \\
\text { Hospital (non- } \\
\text { accredited) } n=60\end{array}$} & \multirow[t]{2}{*}{$\underset{\text { t-test }}{\text { Independent }}$} & \multirow[t]{2}{*}{${ }^{t}$ P-value } \\
\hline & & $\begin{array}{l}\text { Mean } \pm \\
\text { SD }\end{array}$ & $\begin{array}{c}\text { Mean } \\
\%\end{array}$ & $\begin{array}{l}\text { Mean } \pm \\
\text { SD }\end{array}$ & Mean \% & & \\
\hline Identify patient correctly & 18 & $\begin{array}{c}17.50 \pm \\
0.88\end{array}$ & 97.2 & $\begin{array}{l}5.40 \pm \\
2.36\end{array}$ & 30.0 & 10.24 & $* * 0.000$ \\
\hline $\begin{array}{l}\text { Improve effective communication among } \\
\text { care givers }\end{array}$ & 12 & $\begin{array}{l}11.86 \pm \\
0.93\end{array}$ & 98.8 & $\begin{array}{c}3.72 \pm \\
1.44\end{array}$ & 31.0 & 10.77 & $* 0.04$ \\
\hline $\begin{array}{l}\text { Improve the safety of high alert } \\
\text { medications }\end{array}$ & 18 & $\begin{array}{l}17.44 \pm \\
1.10\end{array}$ & 96.9 & $\begin{array}{c}4.26 \pm \\
2.18\end{array}$ & 23.7 & 5.01 & $* * 0.000$ \\
\hline $\begin{array}{l}\text { Ensure correct site, correct procedure and } \\
\text { correct patient surgery }\end{array}$ & 14 & $\begin{array}{c}13.88 \pm \\
0.68\end{array}$ & 99.1 & $\begin{array}{c}3.99 \pm \\
1.59\end{array}$ & 28.5 & 8.99 & $* * 0.000$ \\
\hline $\begin{array}{l}\text { Reduce the risk of health care associated } \\
\text { infections }\end{array}$ & 16 & $\begin{array}{l}15.55 \pm \\
1.48\end{array}$ & 97.2 & $\begin{array}{l}6.10 \pm \\
2.25\end{array}$ & 38.1 & 6.98 & $* * 0.000$ \\
\hline $\begin{array}{l}\text { Reduce the risk of patient harm resulting } \\
\text { from fall }\end{array}$ & 12 & $\begin{array}{l}11.86 \pm \\
1.20\end{array}$ & 98.9 & $\begin{array}{c}3.64 \pm \\
1.59\end{array}$ & 30.3 & 6.78 & $* * 0.000$ \\
\hline Total knowledge & 90 & \multicolumn{2}{|c|}{$88.09 \pm 6.27$} & \multicolumn{2}{|c|}{$27.11 \pm 11.41$} & 10.71 & $* * 0.000$ \\
\hline
\end{tabular}

*statistical significance difference $(p \leq 0.05)$

Table (4): Comparison between accredited and non-accredited hospitals regarding knowledge of international patient safety goals among studied staff nurses $(n=112)$

\begin{tabular}{|c|c|c|c|c|c|c|c|}
\hline \multirow[t]{2}{*}{ International patient safety goals } & \multirow[t]{2}{*}{$\begin{array}{c}\text { Maximum } \\
\text { score }\end{array}$} & \multicolumn{2}{|c|}{$\begin{array}{c}\text { Elaraby } \\
\text { International } \\
\text { Hospital } \\
\text { (accredited) } \\
\mathbf{n = 5 2} \\
\end{array}$} & \multicolumn{2}{|c|}{$\begin{array}{c}\text { Benha } \\
\text { University } \\
\text { Hospital (non- } \\
\text { accredited) } \\
\text { n=60 } \\
\end{array}$} & \multirow[t]{2}{*}{$\underset{\text { t-test }}{\text { Independent }}$} & \multirow[t]{2}{*}{ P-value } \\
\hline & & Mean \pm SD & $\begin{array}{c}\text { Mean } \\
\%\end{array}$ & $\begin{array}{l}\text { Mean } \pm \\
\text { SD }\end{array}$ & $\begin{array}{c}\text { Mean } \\
\%\end{array}$ & & \\
\hline Identify patient correctly & 21 & $20.04 \pm .01$ & 95.43 & $5.24 \pm 1.37$ & 24.95 & 19.69 & $* * 0.000$ \\
\hline $\begin{array}{l}\text { Improve effective communication } \\
\text { among care givers }\end{array}$ & 15 & $\begin{array}{c}14.23 \pm \\
1.87 \\
\end{array}$ & 94.87 & \begin{tabular}{|c}
$3.55 \pm$ \\
2.16
\end{tabular} & 23.67 & 52.78 & $* * 0.000$ \\
\hline $\begin{array}{l}\text { Improve the safety of high alert } \\
\text { medications }\end{array}$ & 33 & $\begin{array}{l}30.52 \pm \\
0.86\end{array}$ & 92.48 & $\begin{array}{c}6.36 \pm \\
1.54 \\
\end{array}$ & 19.27 & 75.20 & $* * 0.000$ \\
\hline $\begin{array}{l}\text { Ensure correct site, correct procedure } \\
\text { and correct patient surgery }\end{array}$ & 6 & $5.98 \pm 0.58$ & 99.67 & $\begin{array}{c}2.96 \pm \\
1.17\end{array}$ & 49.33 & 50.67 & $* * 0.000$ \\
\hline $\begin{array}{l}\text { Reduce the risk of health care } \\
\text { associated infections }\end{array}$ & 24 & $\begin{array}{l}23.43 \pm \\
1.03\end{array}$ & 97.63 & $\begin{array}{l}4.88 \pm \\
2.03\end{array}$ & 20.33 & 60.96 & $* * 0.000$ \\
\hline $\begin{array}{l}\text { Reduce the risk of patient harm } \\
\text { resulting from fall }\end{array}$ & 9 & $8.73 \pm 1.64$ & 97.0 & $\begin{array}{c}2.84 \pm \\
1.14\end{array}$ & 31.56 & 26.97 & $* * 0.000$ \\
\hline $\begin{array}{c}\text { Total practice } \\
\end{array}$ & 108 & $102.93 \pm 5$ & 5.99 & $25.83 \pm$ & 9.41 & 63.51 & 0.000 \\
\hline
\end{tabular}

**highly statistical significance difference $(\mathrm{p} \leq \mathbf{0 . 0 0 1})$ 


\section{Discussion}

The findings of the present study illustrated that, more than half of studied staff nurses' were aged from 20 to less than 25 years at both hospitals. About three fifths of studied staff nurses were males at Elaraby International Hospital that was accredited from JCI. While, more than three quarters of them were females at Benha University Hospital that was non-accredited and more than half of them were married at both hospitals.

As regarding the educational level, nearly three quarters of studied staff nurses had Bachelor of nursing science at accredited hospital on the other hand, the vast majority of them had associate degree of nursing at non-accredited hospital and more than half of studied staff nurses had experience 5 years and worked at all shifts "rotate" at both hospitals. From the investigator point of view these years of experience is being due to most of them were newly graduated. Additionally, the vast majority of studied staff nurses had attended previous courses at accredited hospital. On the contrary, the majority of them didn't receive previous courses about patient safety at non-accredited hospital.

These might be due to female nurses in Egypt are predominant and male nurses are new comers to the nursing profession, beside that male nurses prefer to work at private hospitals such as Elaraby International Hospital for higher salaries, unlike most of female nurses prefer to work in the governmental hospitals such as Benha University. Staff nurses had associate degree of nursing at governmental hospitals reflects the fact that large numbers of diploma school nurses are graduated every two years compared to bachelor degree nurses and most of these nurses were compulsory assigned to the hospital for two years by the Ministry of Health and they didn't receive training courses due to lack of nursing education and quality team roles that may affect negatively on their performance of patient safety. However, the private hospitals mainly target is nurses having Bachelor of nursing science and there are nursing education and quality teams that give all nursing staff continuous obligatory courses especially about patient safety.

These findings supported by Mady, Alrafay and Tantawi (2017) mentioned that nurses age of the studied sample were ranging from 20 years to less than 25 years, more than two thirds of sex were females, and more than half of nurses had associate degree of nursing, while one fifth of them were bachelor, more than one third of education had less than 5 years of experiences, and more than three quarters of them did not attend training program regarding patient safety.

Regarding to total knowledge levels of international patient safety goals among studied staff nurses at study setting, the results of the present study revealed that, the vast majority and more than one quarter of studied staff nurses had good knowledge level about international patient safety goals at accredited (Elaraby International) and nonaccredited (Benha University) hospitals respectively. This might be due to nearly all staff nurses at accredited hospitals had received continuous educational courses about international patient safety goals, that may have affect positively on their knowledge about IPSG, there is orientation course for new hired staff nurses and monthly educational calendar for old staff nurses about IPSGs and there were a written and announced policies about IPSGs at all units. Conversely, staff nurses at non-accredited 
hospitals didn't receive educational courses about IPSGs and there was no policies about IPSGs at units.

The result of the present study for non-accredited hospital was supported with Eldeeb, Ghoneim and Eldesouky, (2016) who conducted study at Shebin Elkom Teaching Hospital which was non-accredited from JCI about perception of patient safety among nurses at teaching hospital and showed that most of the nurses had poor knowledge regarding IPSGs.

These findings for non-accredited hospital were contraindicated with Al-Rafay, Shafik and Fahem, (2018) who conducted study to assess nurses' performance regarding IPSG at Primary Health Care settings in ElBadrashine directorate, which were nonaccredited from JCI and illustrated that, more than two-fifths of studied nurses had good knowledge regarding IPSGs and near to one third had poor knowledge, while the rest of them had average knowledge.

Regarding to total practice levels of international patient safety goals among studied staff nurses at study setting, the results of the present study revealed that the vast majority of studied staff nurses competently applied international patient safety goals at accredited hospital (Elaraby International). Conversely, about three quarter of them incompetently applied international patient safety goals at non-accredited hospital (Benha University).

These might be due to nearly all of staff nurses at accredited hospitals had received training about patient safety practices that may have affect positively on their application of international patient safety goals, written policies of international patient safety goals are being present in all hospital units and announced to all nursing staff, all consumables and resources for the application of IPSGs are available at any time for all patients and there was IPSGs key performance indicators (KPIs) and committees for monitoring the application of IPSGs and prevent any potential problems. But, most of staff nurses at non-accredited hospitals hadn't received training about patient safety practices, that may have affect negatively on their application of international patient safety goals, there aren't any written policies of IPSGs in the unit and there was lack of consumables and resourced related to the application of international patient safety goals.

This result for non-accredited hospitals was similar with the study carried out by Shaheen, Mahros, Hegazy and Salem, (2016) at El-Ebor family health centers which were not-accredited from JCI to assess healthcare providers practice toward Patient Safety" and illustrated that the majority of the participants had unaccepted practice regarding IPSGs.

Moreover, this finding for nonaccredited hospitals was contraindicated with the study carried out by Brasaite, Kaunonen, Martinkenas, Mockiene and Suominen, (2017) showed that the majority of health care professionals were competent regarding IPSGs skills.

Regarding correlation between studied staff nurses' knowledge and practice of international patient safety goals at study setting, the result of the present study revealed that there was positive spastically significant correlation between studied staff nurses' knowledge and practice of international patient safety goals at accredited and non-accredited hospitals. From the investigator point of view this might be due to when technical skills increased, cognitive 
skills increased spontaneously. This result was supported with the study carried out by Al-Rafay, Shafik and Fahem, (2018) illustrated that there was statistically significant difference between nurses' knowledge and practice regarding to international patient safety goals.

Regarding comparison between accredited and non-accredited hospitals regarding knowledge and the application of international patent safety goals among studied staff nurses, the result of the present study confirmed that there was highly statistically significant difference between accredited and non-accredited hospitals regarding knowledge and the application of international patient safety goals among studied staff nurses. This might be due to accredited hospitals consider patient safety apriority during patient hospitalization for high quality patient care without any error, on the contrary non-accredited hospitals.

\section{Conclusion}

The majority of studied staff nurses had good knowledge and competent applied practices levels of international patient safety goals at accredited hospitals while, more than one quarter had good knowledge and about three quarters of them had incompetent applied levels of international patient safety goals at non-accredited hospitals. Moreover, there was positive statistically significant correlation between studied staff nurses' knowledge and practice of international patient safety goals at accredited and nonaccredited hospitals.

Additionally, there was highly statistically significant difference between accredited and non-accredited hospitals regarding knowledge and application of international patient safety goals among studied staff nurses'.

\section{Recommendations}

* Designing a blame-free system for identifying threats to patient safety, sharing information and learning from events.

* Reinforcing the system of application the international safety goals in hospital through quality auditing process such as using key performance indicators for continuous evaluation of the application of international patient safety goals.

* Educational programs and training courses should be developed and implemented for staff nurses about application of international patient safety goals and how it can be used to improve patient safety at non-accredited hospitals.

* Reapplication of the study on the large probability sample and settings to provide strong evidence about application of international patient safety goals.

\section{References}

Aboshaiqah, A. and Baker, O. (2013). Assessment of nurses' perceptions of patient safety culture in a Saudi Arabia hospital Journal of Nursing Care Quality, 28(3); 272280.

Al-Rafay, S., Shafik, S. and Fahem, S. (2018). Assessment of nurses' performance regarding international patient safety goals at Primary Health Care Settings. IOSR Journal of Nursing and Health Science (IOSR-JNHS), 7(6); 59-67.niversity, pp: 41-42.

Brasaite, I., Kaunonen, M., Martinkenas, A., Mockiene, V. and Suominen, T. (2017). Health care professionals' knowledge regarding patient safety. Clinical Nursing Research, 26(3); 250-300.

Ebrahim, S., Mohamed, S. and Ahmed, E. (2019). Nursing students and educators' perception toward clinical instructional experience at secondary technical nursing 
schools. Unpublished master thesis. Faculty of Nursing, Benha U.

Eldeeb, A., Ghoneim, M. and Eldesouky, K. (2016). Perception of patient safety among nurses at teaching hospital. American Journal of Nursing Science, 5(1); 122-128.

Joint Commission International (JCI). (2014). Joint commission international standards for hospitals. Retrieved from: from :http://www.jcaho.org/accredited+organizatio ns/patient+safety/npsg.htm. last accessed at January, 2018.

Khater, W., Akhu-Zaheya, L., Al-

Mahasneh, S.and Khater, R. (2015).Nurses' perceptions of patient safety culture in Jordanian hospitals. International Nursing Review, 62(1); 82-91.

Mady. H., Alrafay, S. and Tantawi, H. (2017). Assessment of the dimensional application of international safety goals for children in hospital. Unpublished master thesis, at Faculty of Nursing, Ain Shams University, pp: 72-79.

Shaheen, M., Mahros, A., Hegazy, N. and Salem, S. (2016). Health care providers practice toward patient safety in El-Ebor family health centers, Egypt, pp: 102-109. Retrieved from: https: // www .semanticscholar .org /paper /Health-care-
Providers-practice-toward-Patient-in- $\% 2 \mathrm{C}$ -

Shaheen-Mahros. Last accessed at February, 2018.

Mousavi,H.,Zeraati, H.,Jabbarv, M., Mokh atre, H., Asadollahi ,A.

and Dargahi, H.(2016). Assessment of patient safety for quality improvement based on joint commission international accreditation standards in Farabi Eye Hospital of Tehran University of Medical Sciences. Journal of Patient Safety \& Quality Improvement, 4(2); 351-357.

Theodosios, S. (2014). The development of patient safety culture. Health Science Journal, 8(2); 234-238.

Zakaria, N., Hamzah, N., Yamin, A., Hamidon, I., Arriffin, A. and Rubani ,K. (2019). Competency in career management among technical university students. International Journal of Academic. Research in business and social sciences, 9(13); 173182.

Zhan, C. (2016). Health services information. $2^{\text {nd }}$ edition. Patient safety research using administrative data. Data and measures in health services research, pp: 124. 


\section{تطبيق الممرضين للأهداف الدولية لسلامة المريض في المستشفيات المعتمدة والغير معتمدة أمير جمال طاحون- سناء مصطفي سعفان - ابتسام سعيد احمد}

تعتبر سلامة المريض هي عنصر أساسي في جودة الرعاية الصحية والتي لا نزال تمثل تحديا للبلدان النامية. و أصبح تقييم تطبيق الأهداف الدولية لسلامة المريض في مؤسسات الرعاية الصحية جزءًا لا يتجزأ من تحسين سلامة المريض. لذلك هدفت هذه الدراسة الي تقييم تطبيق المدرضين للأهداف الدولية لسلامة المريض في المستشفيات المعتمدة وغير المعتمدة. وقد أجريت الدراسة في وحدات العناية المركزة العامة في مستشفى بنها الجامعي (مستشفى غير معتمد) و المستشفى العربي الدولي (مستشفى معتمد). حيث كثفت النتائج أن الغالبية العظمى من الممرضين لديهم مستوى جيد من المعرفة وطبقوا بمستوي كفاءة عالية في المستشفيات المعتمدة حول الأهداف الدولية لسلامة المريض .من ناحية أخري، أكثر من الربع لديهح مستوى جيد من المعرفة و أكثر من ثلاثة أرباع طبقو ابمستوي غير كفء في المستشفيات غير المعتمدة حول الأهداف الدولية لسلامة المريض. كما أوصت الدراسة بأهمية بإجراء برامج تعليم مستمر ودورات تدريبية للممرضين حول تطبيق الأهداف الدولية لسلامة المريض وكيف يمكن استخدامها لتحسين سلامة المريض في المستشفيات غير المعتمدة. 